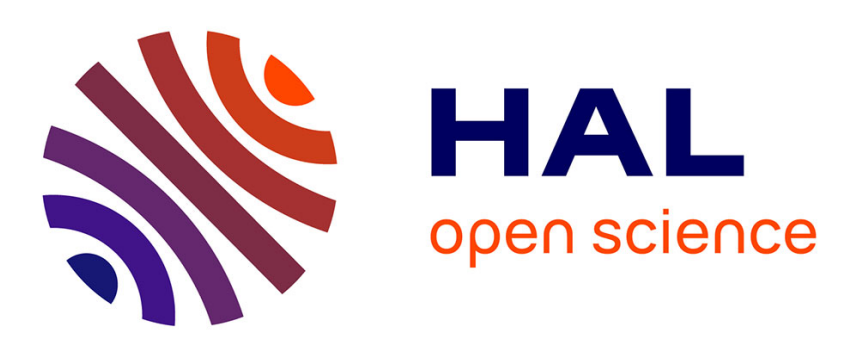

\title{
Oxygen sublattice defect in cobalt oxide: formation, migration, charge localization and thermodynamic processes
}

\author{
R.J. Tarento
}

\section{- To cite this version:}

R.J. Tarento. Oxygen sublattice defect in cobalt oxide: formation, migration, charge localization and thermodynamic processes. Revue de Physique Appliquée, 1989, 24 (6), pp.643-647. 10.1051/rphysap:01989002406064300 . jpa-00246089

\section{HAL Id: jpa-00246089 https://hal.science/jpa-00246089}

Submitted on 1 Jan 1989

HAL is a multi-disciplinary open access archive for the deposit and dissemination of scientific research documents, whether they are published or not. The documents may come from teaching and research institutions in France or abroad, or from public or private research centers.
L'archive ouverte pluridisciplinaire HAL, est destinée au dépôt et à la diffusion de documents scientifiques de niveau recherche, publiés ou non, émanant des établissements d'enseignement et de recherche français ou étrangers, des laboratoires publics ou privés. 


\title{
Oxygen sublattice defect in cobalt oxide : formation, migration, charge localization and thermodynamic processes
}

\author{
R. J. Tarento \\ Laboratoire de Physique des Matériaux, 1 Place Aristide Briand, 92295 Meudon, France
}

(Reçu le 19 décembre 1988, révisé le 20 février 1989, accepté le 24 février 1989)

\begin{abstract}
Résumé. - Dans l'article présent, nous avons étudié la formation et la migration des défauts d'oxygène dans $\mathrm{CoO}$ en utilisant des simulations classiques. La localisation de la charge pour la lacune d'oxygène a montré que les électrons sont sur des sites cobalt. Nous nous sommes intéressés à la possibilité de formation d'interstitiels d'oxygène. En accord avec les résultats de Dieckmann, nous avons trouvé que l'énergie de migration de la lacune est indépendante de son état de charge. Dans la dernière partie, nous avons étudié les processus thermodynamiques de formation des défauts par mécanisme d'échange entre le solide et l'atmosphère.
\end{abstract}

\begin{abstract}
In the present article we have studied the formation and migration of oxygen defects in $\mathrm{CoO}$ using classical simulations. The charge localization in the oxygen vacancy has shown that the electrons are on cobalt sites. Molecular interstitial formation has been investigated. In agreement with Dieckmann's results, we have found that the migration energy of the vacancy is independent of the charge state. In a last part, we have derived the thermodynamic processes for the reaction of defect formation between the solid and the atmosphere.
\end{abstract}

\section{Introduction.}

Cobalt oxide is a $\mathrm{NaCl}$ structure compound which exhibits a non-stoichiometry which is attributed to cobalt sublattice defects (chiefly cobalt vacancies) [1]. The defect concentration in the oxygen sublattice is several orders of magnitude smaller, but nevertheless some physical processes like oxidation or creep are governed by them. Creep [2] and oxygen self diffusion [3] experiments have been the privileged techniques to characterize their nature : at low oxygen partial pressure oxygen vacancies, and at high oxygen pressure interstitials. Their charge state and their diffusion coefficient have been derived [3]. However some questions have not yet been solved, for example, concerning either the localization of the charge or the contribution of the migration and the formation to the diffusion. In order to pursue these questions, simulation is a good technique.

In the present article, we have carried out the calculation of the energy and the entropy for the formation and the migration of defects versus their charge state. In a first part, classical static calcu- lations have been done using H.A.D.E.S. (Harwell Automatic Defect Energy Simulation) and S.H.E.O.L. (Simple Harmonic Evaluation of Lattice) codes. In the last part we have derived the chemical reactions for the defect formation obtained by reaction between the material and the ambient atmosphere.

\section{Classical static simulation.}

The calculations have been carried out to study the free energy. The procedure has been reviewed in previous articles [4]. Here we summarize the idea of the simulation: the internal energy is obtained by dividing the defect crystal into two zones : the zone I containing the defect is treated atomistically, the remaining crystal (zone II) is considered like a continuum treated in the Mott-Littleton model [5]. Pairwise interactions are considered. The potentials that we have used are these of Sangster-Stoneham [7]. The polarization effects are studied with the shell model [7]. 


\subsection{DEFECT FORMATION.}

2.1.1 Oxygen vacancies. - Removal of an oxygen anion from its site creates a double charged oxygen vacancy (the charge is the relative charge compared with the site charge), noted $V_{O}^{\circ \bullet}$ in the Kröger-Vink notation [1]. If $V_{O}^{\circ \bullet}$ traps one or two electrons, it is transformed into $V_{O}^{\circ}$ or $V_{O}^{x}$ which are respectively single charged or neutral vacancies. The localization of the charge is one of the most important problems for $V_{O}^{*}$ and $V_{O}^{x}$ : the electron could be either on the vacancy site (like a $\mathrm{F}$ centre) (Fig. 1a) or on a cobalt site (Fig. 1b). The second possibility is energetically the more favorable : for $V_{O}^{\circ}$ the energy difference is $1.5 \mathrm{eV}$ and moreover the electrons have a trend of being located on the nearest cobalt sites; for $V_{O}^{x}$, the two electrons are localized on sites such that the repulsion is screened (Fig. 1c). The internal
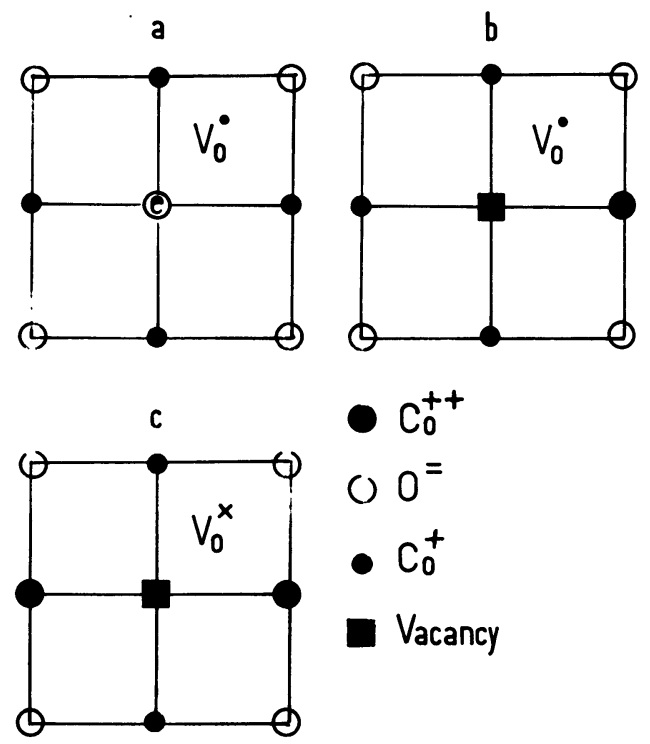

Fig. 1. - Oxygen vacancies: a) single charge vacancy $\left(V_{0}^{*}\right)$ with electron trapped on the oxygen site ; b) single charge vacancy $\left(\mathrm{V}_{\mathrm{O}}^{\circ}\right)$ with electron trapped on the cobalt site ; c) neutral vacance $V_{0}^{x}$.

energy, the entropy and the free energy to create $\mathrm{V}_{\mathrm{O}}^{\mathbf{0}}, \mathrm{V}_{\mathrm{O}}^{\mathbf{0}}$ and $\mathrm{V}_{\mathrm{O}}^{\mathrm{x}}$ are reported in table $\mathrm{I}$. It is worth noting that in a crude fully opposite theory $V_{0}^{\bullet}$, $V_{O}^{x}$ could be imagined like a « hydrogenoid vacancy » where the electron is gravitating around the oxygen site on an orbit of radius $3 \AA$ given by the « Bohr radius ", which is not very much larger than the oxygen-cobalt distance $(2.2 \AA)$ obtained with the present calculation.

2.1.2 Oxygen interstitial. - Oxygen interstitials are located in the tetrahedral sites like for cobalt ones (the energy difference between the tetrahedral and octahedral site is $1 \mathrm{eV}$ ). But because of the oxygen interstitial overcrowding, we could wonder whether
Table I. - Internal energy $\left(u_{\mathrm{v}}^{\mathrm{f}}\right)$ and entropy $\left(s_{\mathrm{v}}^{\mathrm{f}}\right)$ for the formation of oxygen defects at the temperature of $1473 \mathrm{~K}$.

\begin{tabular}{|c|c|c|}
\hline Defect & $u_{\mathrm{v}}^{\mathrm{f}}(\mathrm{eV})$ & $s_{\mathrm{v}}^{\mathrm{f}}(\mathrm{k})$ \\
\hline $\mathrm{V}_{\mathrm{O}}^{\circ \bullet}$ & 23.76 & -5.45 \\
\hline $\mathrm{V}_{\mathrm{O}}^{\circ}$ & 39.3 & -4.87 \\
\hline $\mathrm{V}_{\mathrm{O}}^{\mathrm{x}}$ & 57.2 & -4.1 \\
\hline $\mathrm{O}_{\mathrm{i}}^{\prime \prime}$ & -13.7 & 4.80 \\
\hline $\mathrm{O}_{\mathrm{i}}^{\prime}$ & 2.1 & 7.01 \\
\hline $\mathrm{O}_{\mathrm{i}}^{\mathrm{x}}$ & 5.2 & \\
\hline$\left(\mathrm{O}_{2}\right)_{\mathrm{i}}^{\prime \prime}$ & -15.2 & \\
\hline$\left(\mathrm{O}_{2}\right)_{\mathrm{i}}^{\prime}$ & 1.1 & \\
\hline
\end{tabular}

it is possible to move ions from their lattice sites in such a way to create a molecular defect of which the electronic configuration is nearly that of the $\mathrm{O}_{2}$ molecule (its geometrical structure is a dumbbell (Fig. 2)). The calculation of the internal energy suggests such a behaviour. The $\mathrm{O}-\mathrm{O}$ distance in the molecular defect is $1.16 \AA$ for $\left(\mathrm{O}_{2}\right)_{\mathrm{i}}^{\prime \prime}$ and $1.25 \AA$ for $\left(\mathrm{O}_{2}\right)_{\mathrm{i}}^{\prime}$ which is in agreement with the O-O distance in the free $\mathrm{O}_{2}$ molecule. The formation energies and entropies for the atomic and molecular interstitials are reported in table $\mathrm{I}$.

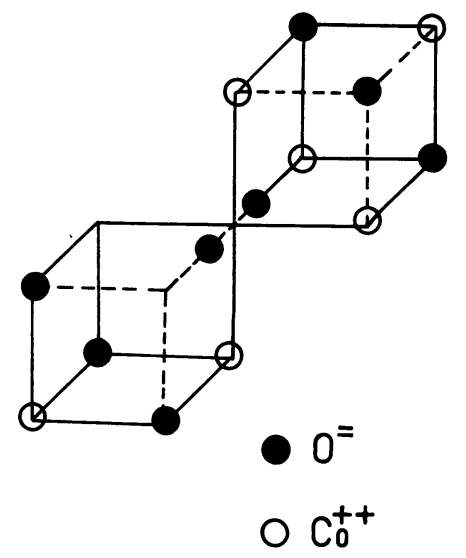

Fig. 2. - Molecular oxygen interstitial: $\left(\mathrm{O}_{2}\right)_{\mathrm{i}}$ : the « Dumbbell structure ».

\subsection{DEFECT MIGRATION.}

Vacancy migration. - Like for $\mathrm{V}_{\mathrm{C}_{0}}^{\prime}$ [8] the saddle point of the $V_{O}^{\circ}$ migration is not located on the octahedral site (A), but is on both sides of $\mathrm{A}$ along 

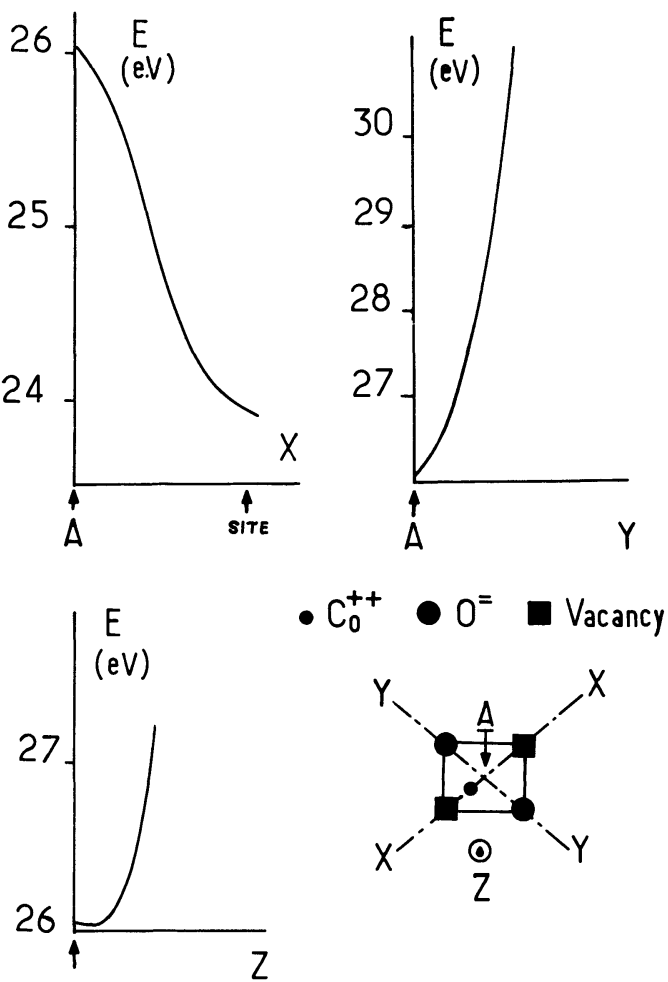

Fig. 3. - Energetic surfaces for $\mathrm{V}_{\mathrm{o}}^{\infty}$ migration.

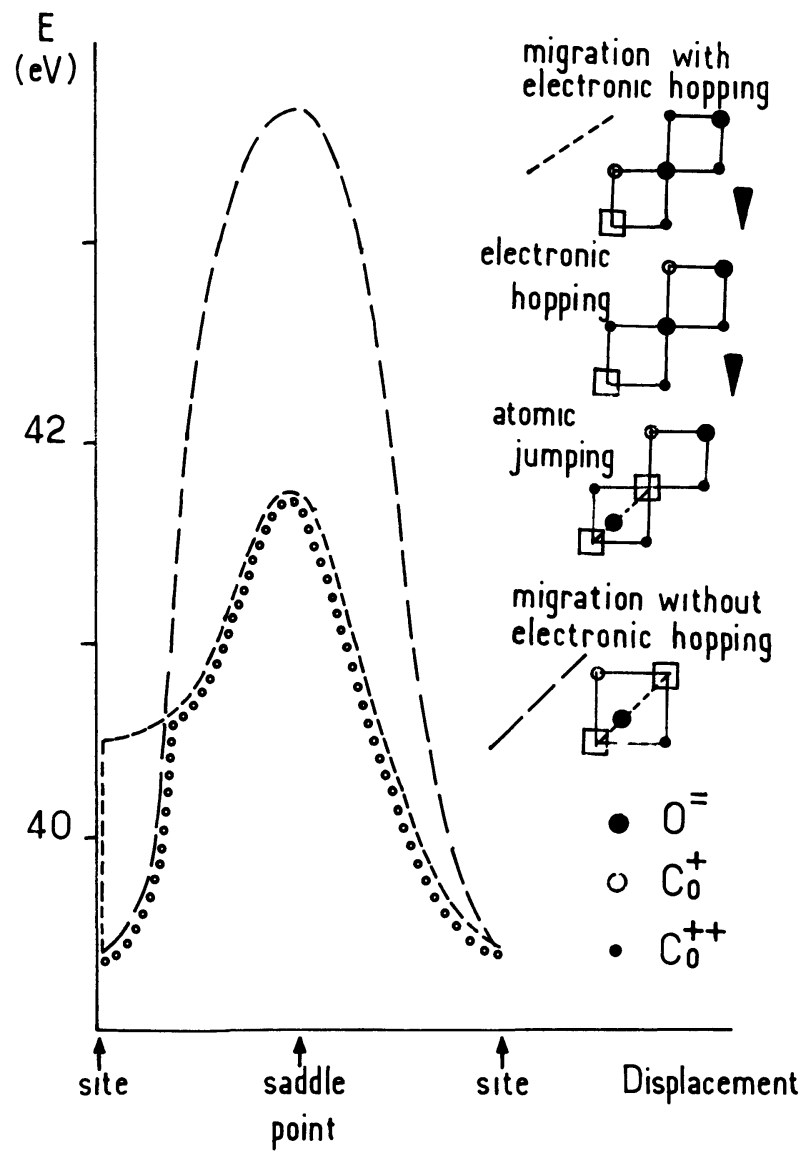

Fig. 4. - Single charged oxygen vacancy $\left(V_{O}^{\circ}\right)$ migration with/without electronic hopping (the dotted line is the migration path). the $\langle 001\rangle$ axis. Figure 3 displays the behaviour of the energy surface in the neighbourhood of $\mathrm{A}$. As the energy depth of the wells is small, Vineyard's model is still valid [6]. The $\mathrm{V}_{\mathrm{O}}^{\mathrm{e}}$ migration energy is of $2.05 \mathrm{eV}$. For the $\mathrm{V}_{\mathrm{O}}^{\circ}$ vacancy, built up with an unoccupied oxygen site plus an electron localized on the nearest cobalt site, the $\mathrm{O}^{=}$jump is energetically prohibitive $(4.25 \mathrm{eV})$, but like for $\mathrm{V}_{\mathrm{C}_{0}}^{\prime}$ [8] an electronic hopping decreases the migration barrier $(2.45 \mathrm{eV})$ (Fig. 4). The $\mathrm{V}_{\mathrm{O}}^{\circ}$ migration energy is slightly higher than that of $\mathrm{V}_{\mathrm{O}}^{\circ}$. The present calculation on oxygen vacancies and the previous one on cobalt vacancies show that the migration energy is independent of the charge state. The simulation results are in agreement with Dieckmann's conclusions [9] derived from experimental fittings. We remark that the same trend is again found in the « hydrogenoid vacancy » model.

The internal energy and entropy of migration, corrected by the quadrupole term obtained by the interaction of the electric gradient field on the unspherical electronic charge density calculated at the temperature of $1473{ }^{\circ} \mathrm{K}$ are reported in table II.

Table II. - Internal energy $\left(u_{\mathrm{v}}^{\mathrm{m}}\right)$ and entropy $\left(s_{v}^{\mathrm{m}}\right)$ for the migration of oxygen defects at the temperature of $1473 \mathrm{~K}$. The entropy is given in $k$ Boltzmann unit.

\begin{tabular}{|c|c|c|}
\hline & $u_{\mathrm{v}}^{\mathrm{m}}(\mathrm{eV})$ & $s_{\mathrm{v}}^{\mathrm{m}}(\mathrm{k})$ \\
\hline $\mathrm{V}_{\mathrm{O}}^{\circ}$ & 1.85 & 2.66 \\
\hline $\mathrm{V}_{\mathrm{O}}^{\circ}$ & 2.25 & 2.93 \\
\hline$\left(\mathrm{O}_{2}\right)_{\mathrm{i}}^{\prime \prime}$ & 0.68 & -0.77 \\
\hline$\left(\mathrm{O}_{2}\right)_{\mathrm{i}}^{\prime}$ & 0.75 & -0.50 \\
\hline
\end{tabular}

\section{Calculation of thermodynamic and transport pro-} cesses for oxygen defects.

The formation entropy and energy calculated in part 2 are those for an exchange between the material and the infinity. However, for the comparison between experiments and theoretical prediction we need to calculate the reaction between the solid and the ambient atmosphere to create the defects. Within the mass-action approximation, we may write down the defect equilibria as chemical reactions: for oxygen vacancies

$$
\begin{aligned}
& \mathrm{O}_{\mathrm{O}}^{\mathrm{x}} \rightleftarrows \mathrm{V}_{\mathrm{O}}^{\mathrm{e}}+\frac{1}{2} \mathrm{O}_{2}+2 \mathrm{e}^{\prime} \\
& \mathrm{O}_{\mathrm{O}}^{\mathrm{x}} \rightleftarrows \mathrm{V}_{\mathrm{O}}^{\bullet}+\frac{1}{2} \mathrm{O}_{2}+\mathrm{e}^{\prime} \\
& \mathrm{O}_{\mathrm{O}}^{\mathrm{x}} \rightleftarrows \mathrm{V}_{\mathrm{O}}^{\mathrm{x}}+\frac{1}{2} \mathrm{O}_{2}
\end{aligned}
$$


for oxygen interstitials

$$
\begin{aligned}
& \frac{1}{2} \mathrm{O}_{2} \rightleftarrows \mathrm{O}_{\mathrm{i}}^{\mathrm{x}} \\
& \frac{1}{2} \mathrm{O}_{2} \rightleftarrows \mathrm{O}_{\mathrm{i}}^{\prime}+\mathrm{h}^{\bullet} \\
& \frac{1}{2} \mathrm{O}_{2} \rightleftarrows \mathrm{O}_{\mathrm{i}}^{\prime \prime}+2 \mathrm{~h}^{\bullet} .
\end{aligned}
$$

In fact we have taken the oxygen vacancy chemical reactions from the Schottky reactions :

$$
\begin{aligned}
& \Phi \rightarrow V_{O}^{\circ \bullet}+V_{C_{0}}^{\prime \prime} \\
& \Phi \rightarrow V_{O}^{\bullet}+V_{C_{0}}^{\prime} \\
& \Phi \rightarrow V_{O}^{x}+V_{C_{0}}^{x}
\end{aligned}
$$

where $\Phi$ is the symbol for the vacuum, and then used previous calculations on cobalt vacancies [10]. The chemical reactions have been reported in table III. To obtain the numbers of table III, we also require some experimental data, such as the electron affinities of oxygen, the enthalpy and entropy of the oxygen molecule dissociation, the third ionization energy of cobalt. These numbers and the relevant

Table III. - Chemical reaction for defect formation in $\mathrm{CoO}$. The entropy is given in $k$ Boltzmann unit.

\begin{tabular}{|c|c|c|}
\hline Defect & $h_{\mathrm{p}}(\mathrm{eV})$ & $s_{\mathrm{p}}(\mathrm{k})$ \\
\hline $\mathrm{V}_{\mathrm{Co}}^{\prime \prime}$ & 1.02 & 0.22 \\
\hline $\mathrm{V}_{\mathrm{C}}^{\prime}$ & 0.34 & -0.55 \\
\hline $\mathrm{V}_{\mathrm{Co}}^{\mathrm{x}}$ & -0.23 & -0.68 \\
\hline $\begin{array}{c}\text { Schottky } \\
\phi \rightarrow \mathrm{V}_{\mathrm{O}}^{\circ}+\mathrm{V}_{\mathrm{Co}}^{\prime \prime}\end{array}$ & 6.92 & 4.06 \\
\hline $\begin{array}{c}\text { Schottky } \\
\phi \rightarrow \mathrm{V}_{\mathrm{O}}^{\circ}+\mathrm{V}_{\mathrm{C} \mathrm{o}}^{\prime}\end{array}$ & 8.34 & 4.06 \\
\hline $\begin{array}{c}\text { Schottky } \\
\phi \rightarrow \mathrm{V}_{\mathrm{O}}^{\mathrm{x}}+\mathrm{V}_{\mathrm{C} \mathrm{o}}^{\mathrm{x}}\end{array}$ & 11.1 & 3.10 \\
\hline $\mathrm{V}_{\mathrm{O}}^{\circ}$ & 7.95 & 3.84 \\
\hline $\mathrm{V}_{\mathrm{O}}^{\circ}$ & 8.11 & 3.2 \\
\hline $\mathrm{V}_{\mathrm{O}}^{\mathrm{x}}$ & 11.4 & 3.8 \\
\hline $\mathrm{O}_{\mathrm{i}}^{\prime \prime}$ & 4.08 & 11.25 \\
\hline $\mathrm{O}_{\mathrm{i}}^{\prime}$ & 6.38 & 2.3 \\
\hline $\mathrm{O}_{\mathrm{i}}^{\mathrm{x}}$ & 7.21 & \\
\hline
\end{tabular}

Table IV. - Experimental numbers used in the calculations.

\begin{tabular}{|c|c|c|}
\hline & Number used & Ref. \\
\hline $\begin{array}{c}\text { Electron affinity of } \\
\text { oxygen (1st+2nd) }\end{array}$ & $748.4 \mathrm{~kJ} . \mathrm{mole}^{-1}$ & $(*)$ \\
\hline Dissociation of $\mathrm{O}_{2}$ & $\begin{array}{l}h_{\mathrm{p}}=249.8 \mathrm{~kJ} . \mathrm{mole}^{-1} \\
s_{\mathrm{p}}=257.7 \mathrm{~J} . \mathrm{mole}^{-1} \mathrm{~K}^{-1}\end{array}$ & {$[12]$} \\
\hline $\begin{array}{c}\text { Ionization energy } \\
\text { of } \mathrm{Co}^{2+}\end{array}$ & $3229.8 \mathrm{~kJ} \cdot \mathrm{mole}^{-1}$ & {$[13]$} \\
\hline
\end{tabular}

(*) Value taken for this work. The number is consistent with the calculation of Mackrodt-Stewart [11].

references are shown in table IV. Electronic contributions to the entropy were ignored. In fact the comparison between experiments and calculations for the oxygen sublattice defects is only possible for diffusion data which are the sum of the migration and formation contributions.

Entropies and enthalpies have been reported in table V. Diffusion enthalpies obtained by simulation or derived from experiments [3] are close for the double charged vacancy $\left(\mathrm{V}_{\mathrm{O}}^{\circ}\right)$ and the double charged interstitials $\mathrm{O}_{\mathrm{i}}^{\prime \prime}$. The agreement is bad for $\mathrm{V}_{\mathrm{O}}^{\circ}$ and $\mathrm{O}_{\mathrm{i}}^{\prime}$. As for the entropies only for $\mathrm{O}_{\mathrm{i}}^{\prime \prime}$ the magnitude is good.

Table V. - Comparison between experiment and theoretical prediction for oxygen defect diffusion. The entropy is given in $k$ Boltzmann unit.

\begin{tabular}{|c|c|c|c|c|}
\hline & $\begin{array}{c}\Delta H^{\mathrm{D}} \mathrm{eV} \\
\exp [3]\end{array}$ & $\begin{array}{c}\Delta H^{\mathrm{D}} \mathrm{eV} \\
\text { calculation }\end{array}$ & $\begin{array}{c}\Delta S^{\mathrm{D}}(\mathrm{k}) \\
\exp [3]\end{array}$ & $\begin{array}{c}\Delta S^{\mathrm{D}}(\mathrm{k}) \\
\text { calculation }\end{array}$ \\
\hline $\mathrm{V}_{\mathrm{O}}^{\mathrm{o}}$ & 9.2 & 9.9 & 26.1 & 7.5 \\
\hline $\mathrm{V}_{\mathrm{O}}^{\circ}$ & 5.1 & 10.6 & 34.1 & 7.1 \\
\hline $\mathrm{O}_{\mathrm{i}}^{\prime \prime}$ & 5.1 & 4.9 & 14.9 & 11.9 \\
\hline $\mathrm{O}_{\mathrm{i}}^{\prime}$ & 5.3 & 7.3 & 8.4 & 2.9 \\
\hline
\end{tabular}

\section{Conclusion.}

The present calculation has specified the charge localization in oxygen vacancies (electron on cobalt site). This result is in agreement with first quantuum calculations (the probability of finding an electron on the oxygen empty site is 0.08 for $V_{O}^{\circ}$ and 0.82 for $\mathrm{V}_{\mathrm{O}}^{\circ}$, the other part of electrons is localized on the six cobalt sites to minimize the repulsions) [14]. The independence of the migration energy with regard to 
the charge state of the vacancy has been obtained, and agrees with Dieckmann's result. The comparison between experiment and theory is quite good for the enthalpy but bad for the entropy. The possibility of having molecular interstitials of oxygen is an interesting problem for the migration where 3 oxygen atoms are at least involved and moreover during the jumping the nature of the bond is changed.

\section{References}

[1] Kofstad J. P., Non-stoichiometry-diffusion and electrical conductivity in binary oxides (Wiley) 1972.

[2] Routbort J. L., Acta Metall. 30 (1982) 663 ; Clauss, C., Tarento R. J., Monty C., Dominguez-R A., Castaing J. and Philibert J., Transport in non-stoichiometry compounds, Nato B Phys. 129 (1985) 280.

[3] TARento R. J., MonTy C., Solid state ionics (1988), in press.

[4] Catlow C. R. A., Mackrodt W. C., Theory of simulation methods for lattice and defects calculations in crystals in Computer simulation of solides, Eds. Catlow, Mackrodt, Lect. Note Phys. (Springer-Verlag, New York) chapter 1 (1982) 166.

[5] Mott N. F., Littleton M. J., Trans. Faraday Soc. 34 (1938) 485-99.

[6] Harding J. H., Phys. Rev. B 32 (1985) 6861-72.

[7] Stoneham A. M., Sangster M. J. L., Philos. Mag. B 52 (1985) 717-27.
[8] Harding J. H., TARento R. J., Defect properties and processes of high technology non-metallic materials, MRS Symposium Proc., Eds. Y. Chen-Kingery and R. J. Stokes (MRS Pittsburg PA) Vol. 60 (1986).

[9] DIECKMANN R., habilitation thesis, Hanover University (1985).

[10] Harding J. H. and Tarento R. J., Advances in ceramics, non stoichiometric compounds 23 (1987) 239.

[11] Mackrodt W. C. and Stewart R. F., J. Phys. C 12 (1979) 5015-36.

[12] CRC Handbook of physics and chemistry, 65th ed., Eds. R. C. Weast, M. J. Astle and W. H. Beger (CRC press Boca Raton FL) 1984.

[13] Moore C. E., atomic energy levels, vol. III, Natl. Bur. Stand. 467 (1958).

[14] Tarento R. J., Thèse de Doctorat d'Etat, Orsay University (1988). 